\title{
Critical Success Factors (CSFs) for Lean Tools and ERP Systems implementation in manufacturing SMEs.
}

\begin{abstract}
The aim of the work presented in this paper is to determine the most important CSFs which have the strongest impact on the implementation of Lean tools and ERP systems within SMEs. To achieve this aim a methodology of two phases was adopted: the first phase was a literature review to identify the set of CSFs that have an impact on the Lean tools and ERP systems' implementation; the second involved the design of a questionnaire and the gathering of data from SMEs regarding the factors which they consider influence the successful implementation of Lean tools and ERP systems. Ten SMEs were involved in completing the questionnaire and the first analysis was based upon the six responses received. This study has indicated that there is a positive correlation between the CSFs for Lean tools and that of ERP systems.
\end{abstract}

Keywords: Lean tools; ERP system; CSFs; SMEs.

Reference to this paper should be made as follows: Alaskari, O., Ahmad, M.M. and PinedoCuenca, R. (xxxx) 'Critical success factors for lean tools and ERP systems implementation in manufacturing SMEs', Int. J. Lean Enterprise Research, Vol. X, No. Y, pp. 000-000.

Biographical notes: Osama Alaskari received his MSc in Computer Added Engineering from Teesside University, UK. Currently, he is doing PhD at the Teesside University. His research interests include Lean tools, ERP systems, SMEs challenge, and benchmarking performance.

M. Munir Ahmad is a Professor at the Teesside University, UK. His research interests include benchmarking and process improvement, supply chain management and enterprise resource planning, with over 100 publications. He is the Founder of Flexible Automation and Intelligent Manufacturing (FAIM) conferences, editor of the International Journal of Robotics and Computer Integrated Manufacturing (Elsevier), external examiner-Dublin City University, Coventry University, University of Central England, a member of QAA-QA panel member for Mechanical, Manufacturing and Aeronautical Engineering, Loughborough University and a member of the Heads of Mechanical and Manufacturing Engineering, Institution of Mechanical Engineers.

Ruben Pinedo-Cuenca received his $\mathrm{PhD}$ in Enterprise Resource Planning Systems from Teesside University. He is a Lecturer at the Teesside University teaching at undergraduate and postgraduate level, and also on short workforce development courses. His primary subjects are manufacturing management, and integrated systems. His research interests include selection and implementation of ERP in SMEs. He published several technical and management papers presented at conferences, on topics related to ERP.

This paper is a revised and expanded version of a paper entitled" Analysis of the CSFs of Lean Tools and ERP Systems in Improving Manufacturing Performance in SMEs". presented at 23rd International Conference Flexible Automation and Intelligent Manufacturing, FAIM, University of Porto, Portugal, 26-28 June 2013. 


\section{Introduction}

The contribution of small-medium enterprises (SMEs) to the enhancement of many economies has been of critical importance. Thus, for future economic prosperity it is important that SMEs increase their productivity. Many SMEs act as suppliers to larger companies; they form a network of small and often specialised businesses, serving as the foundation of well-functioning economies. In the United Kingdom (UK) SMEs represent $99.6 \%$ of all businesses, accounting for $49.5 \%$ of the economic added value, $54.3 \%$ of employment in the private non-financial sector and $37 \%$ of SMEs are active in the high-tech manufacturing and knowledge intensive service sectors, which are considered a key for the future competitiveness of the country (European Commission, 2012).

Currently, SMEs are struggling to maintain their competitiveness as the market pressure increases daily, due to the growing importance of global supply chain management; for example larger companies require their SMEs suppliers to provide higher quality products or services with faster delivery at lower cost (Underdown and Tallury, 2002). Improvements in competitors' capabilities have shortened product life cycles, elevated product complexity and expanded accessibility to new technical breakthroughs (Gupta and Cawthon, 1996).

The large companies increasing demand for high quality products and cutting edge processes has left the SMEs with little choice but to consider the introduction of continuous improvement methods in addition to the application of Information Technology (IT) techniques. Jiju et al., (2005) stated that, one way in which SMEs can provide larger companies with high quality products or services at lower cost was through the adoption of quality management and the principles of continuous improvement.

There are many tools, techniques, and methodologies that SMEs can adopt to improve both their performance and customers satisfaction, such as: Total Quality Management (TQM), Supply Chain Management, Six Sigma, Lean tools, Material Requirements Planning (MRP), Manufacturing Resource Planning (MRP II) and Enterprise Resource Planning (ERP) systems. Lean tools and ERP systems have begun to be the subject of greater attention from enterprises, including their application in the SMEs; therefore, this paper aims to outline some of the factors that are perceived to be the CSFs for Lean tools and ERP systems within the SME context; and the relationship, if any, between these factors will be examined. As the large companies normally have the resources needed to implement Lean tools and ERP system, naturally the possibility of implementing these methods successfully is high. There is still little documented evidence of their implementation within SMEs. It may be that SMEs require that the implementation costs, subsequent benefits and important CSFs for Lean tools and ERP systems adoption need to be projected upfront. Thus, the two following assumptions were posed:

Assumption 1: There are some common factors among the CSFs for Lean tools and ERP systems.

Assumption 2: There is a high degree of correlation between the CSFs for Lean tools and ERP systems.

To verify these assumptions, the CSFs in the implementation process for Lean tools and ERP systems were identified through the literature review and industrial survey conducted within SMEs.

This paper is structured as follows: first section, the literature related to CSFs, ERP systems and Lean tools are reviewed; the next section outlines the methodology employed for the study; followed 
by the results and discussion section; and finally a summary of the main findings, and recommendations for the SMEs consideration with suggestions for further research. The findings of the study are crucial for the SME owner/managers embarking on the promoting of Lean tools and ERP systems. The results should also assist decision-makers in identifying factors that may distinguish between successful and unsuccessful Lean tools and ERP proposed for implementations in SMEs. Also explained are specific factors that may have more influence on the adoption of Lean tools and ERP in the SMEs; finally, the need for more research that is directly focused on Lean tools and ERP systems in SMEs is reinforced.

\section{Research background}

\subsection{Critical success factors.}

Critical success factors (CSFs) were proposed by Daniel (1961), and popularised by Rockart (1979). CSFs are the term for elements which must be accomplished in any project or company to achieve their mission Oakland (1995). According to Boynton and Zmud (1984), CSFs are defined as the vital construct to ensure success for an organisation's management. This definition is considered to be more general and, therefore, can be relevant to all sectors; however, the definition of success differs between individuals depending on their perspective (Alaskari et al., 2012). Gopal et al., (1999) stated that CSFs are the few things that must go well to ensure success for a manager and/or organisation and they have to represent managerial areas that need to be given special and continual attention to lead to high performance.

Brotherton and Shaw (1996) defined CSFs as the essentials that must be achieved by the company leading to the improvement of its capability to provide the greatest competitive leverage; the authors accentuate that CSFs are not objectives, but are the actions and the processes that can be controlled by management to attain the organisation's objectives. Whilst, Joel and Bruno (1984) defined CSFs as "those characteristics, conditions or variables that, when properly sustained, maintained, or managed, can have a significant impact on the success of a firm competing in a particular industry". CSFs methods have been broadly used in different fields of study to define the critical key factors that impact on the enterprise's success (Lin et al., 2004). Consequently, in the current study the CSFs are observed as the elements that must be attained in order to ensure the successful implementation of Lean tools and ERP systems. Companies which study CSFs permit them to focus their efforts on specific aspects, and decide whether they have the necessary capability to meet CSFs requirements (Boynton and Zmud, 1984). The CSFs are the most important concept for achieving overall organisational objectives, mission and strategies (Freund, 1988).

\subsection{Enterprise resource planning (ERP)}

Recently, ERP systems have been considered to be one of the most widespread IT solutions. ERP has become a key tool for companies to build strong capabilities, improve performance, undertake improved decision making and achieve a competitive advantage (Al-Mashari and Al-Mudimigh, 2003). According to Marnewick and Labuschagne (2005) ERP enables companies to automate and integrate the majority of their business processes, share common data and practices across the company and to produce and access information in a real-time environment. ERP has also been considered as an essential link to enhance integration between all functional areas within the manufacturing enterprise and between the enterprise and its upstream and downstream trading partners (Joseph et al., 2003). However, in spite of the value of ERP systems to the companies, many studies have reported that the failure rate of ERP system implementation is very high, which threatens to breakdown the core operations of the organisation. 
Chronicles (2003) found that only 34\% of IT projects undertaken by Fortune 500 companies were successfully completed. Seymour et al., (2007) stated that approximately $50 \%$ of all ERP implementations fail to meet the expectations of the companies and this view was supported by Sean et al. (2005). Other studies have indicated that the percentage was higher than 50\%; and Majed (2000) reported that $70 \%$ of ERP implementations did not achieve their estimated benefits. Parr and Shanks (2000) stated that the past studies reflect that the failure percentage of ERP systems ranges from $40 \%$ to $90 \%$. Langenwalter (2000) found that the percentage of ERP implementations that can be classified as failures ranges from $40 \%$ to $60 \%$ or higher. Moreover, failure can appear in several forms. Many researchers have stated that numerous ERP implementations exceed both the set budget and scheduled time. According to Panaroma Consulting's ERP report (2010), 54\% of ERP implementation exceeds the allocated budget and 57\% take more than the expected time to implement. Parr and Shanks, (2000) stated that many ERP systems implementations were neither completed on time nor within budget.(Christopher and Light 1999); Fitz-Gerald and Carroll 2004) mentioned that a survey of 117 companies involved in ERP implementation led to the finding that $25 \%$ of ERP projects were over budget, $20 \%$ were terminated before implementation and $40 \%$ of the respondents confirmed that ERP projects' failed to achieve business objectives.

Failures of ERP system implementation projects have been known to lead to bankruptcy (Davenport, 1998; Markus et al., 2000b). In 1996, FoxMeyer Drugs, a \$5 billion wholesale drug distribution company, argued that one of the major problems that led to their bankruptcy was a failed ERP system (Judy and Vessey, 2002). Generally, the failure rate of implementing an ERP system is considered to be fairly high. As a result of the above literature, the study of CSFs of ERP systems was highly pertinent; therefore, many studies have been conducted in this area. However, previous studies in CSFs of ERP within the SME context have been undertaken by many researchers. (Bernroider and Koch 2001; Huin, 2004; Sun et al., 2005; Brent et al., 2009; Doom et al., 2010; and Ahmad and Pinedo Cuenca 2013). Huin (2004) found that unless the differences between SMEs and large firms are understood, managing ERP projects in SMEs "will continue to be slow, painful and at times even unfruitful". Although the benefits of a properly implemented ERP system are potentially great whilst the cost of a poorly implemented system can be greater; and there is significant evidence of increasing global implementation failures in ERP projects and their consequences. This calls for a better understanding of CSFs and these issues must be addressed and well-managed in order for ERP implementation to be successful, (Chockalingam and Ramayah, 2013; Sternad and Bobek, 2006). Due to the complexity of the implementation and its cross-functional nature, the implementation of ERP within companies is not an easy task and does not always prove successful (Ramayah et al., 2007; Judy and Vessey, 2002), as witnessed by the many reports of unsuccessful ERP implementations within business.

\subsection{Lean tools}

The Lean manufacturing term was first introduced in 'The Machine That Changed the World', which describes the Toyota Motor Corporation Production System (TPS) (Womack et al., 1990). The Lean manufacturing principles have gained broad acceptance in modern manufacturing and their application is a pre-requisite for success in international competition (Matt, 2008). Lean principles have different tools and techniques that make them flexible on implementation in any industry; for example; total quality management (TQM), failure mode and effect analysis, five sigma (5S), quality function deployment, Kaizen, Kanban, Value stream mapping (VSM), (Alvarez et al., 2009; Salem et al.,2006; Rachna and Ward 2007). Lean tools start from the premise of adding value and reducing waste, which are the primary goals of all business processes. Many companies have reported some 
benefits when they moved towards becoming Lean by adapting different Lean tools such as Just-inTime (JIT), setup reduction, 5S, Total Productive Maintenance (TPM), (Abdulla, 2003). The literature indicates that most practitioners and researchers have highlighted the application of Lean tools to reduce inventories, lead times, rapid product development processes; these tools include SingleMinute Exchange of Die (SMED), Pull system (Kanban),TPM, Mistake Proofing (Poka Yoke), 5S, Value Stream Mapping, JIT, Visual Management, One Piece flow (Takt Time), Standardised Procedures/work, Kaizen Bicheno (2009). The implementation of Lean tools like any other productivity improvement initiative has enormous difficulties. Different Lean tools and Lean principles can be used to reduce waste and non-value added activities (NVA) in manufacturing; conversely, not all Lean implementations have produced such results (Tyson and Heath 2009). Sohal and Eggleston (1994) stated "that only 10 per cent have the philosophy properly instituted". In addition to that Baker (2002) mentioned that less than 10 per cent of UK organisations have accomplished successful Lean implementation.

According to Farzad and Wong (2011) the significant reasons behind the failure of the Lean practices are the lack of an effective implementation methodology, a clear understanding of Lean performance and its measurement. Companies in the process of implementing Lean tools are facing challenges and difficulties, which could be avoided by identifying the CSFs for Lean tools; in other words, there are several CSFs, which if identified and properly understood, will support and overcome these obstacles and difficulties (Khaled, 2007). Therefore, the study and understanding of the CSFs for Lean tools is essential.

\section{Methodology.}

In this study, two methods have been employed: a literature review and survey. These methods were selected due to the level of funding available for this work; hence this is an exploratory study, from which further work in this field could subsequently be developed; Figure 1 shows the research methodology scenario.

The methodology used in this study focused primarily on the CSFs for Lean tools and ERP systems. The first stage of the methodology was to derive keywords that would be utilised in searching for topics related to CSFs for Lean tools and ERP systems. A comprehensive literature review was conducted by searching hundreds of articles from journals and conference papers, based on the identified keywords in an initial research in the literature. This research involved a high level of analysis of a plethora of journal articles and conference papers and subsequently an extensive Internet search via several search engines, such as Google Scholar, and journal related databases including Scopus, Science Direct, Emerald Intelligence and IEEE Transactions.

Initial research into the literature review was conducted in order to select keywords, which were utilised in searching for related topics and focused on the required subject. The alternative keywords or phrases that describe the concept were determined; this provided a number of different keywords, which were combined to search for additional information, for instance critical success factors, lean tools, lean manufacturing, enterprise resource planning, ERP success factors, and ERP implementation. Since journal articles may not use identical terms for describing a given topic, alternative terms, American / UK spelling, singulars and plurals were taken into account. To ensure that search processes within databases obtained the best results, several techniques including Boolean operators (AND, OR and NOT) wildcards and phrase searching keywords and terms were used. When a fruitful result was found, it was used as a launch pad to examine any record which was particularly relevant to the subject, by searching into their references, thus providing further references. This 
research identified many CSFs for Lean tools when the focus was on the words themselves and not on their meaning. However, after comparing and contrasting these CSFs, the similarities thus detected caused the number for CSFs to be reduced to the key factors fundamentally critical for the implementation of Lean tools; these factors are presented in Table 2. Similar steps were carried out to identify CSFs for ERP systems and these are presented in Table 3. Although the review of the literature has provided considerable amount information on CSFs for both Lean tools and ERP systems, the importance and weight for each factor could not be determined.

Therefore, the need for further research within some of the existing SMEs that had experience in Lean tools and ERP system implementation was highlighted to identify the importance and weight for each factor to determine the weight of factors deemed critical for categorising the CSFs for Lean tools and ERP systems to enable SMEs to focus on the most important factors in order of priority. Thus the identified CSFs for Lean tools and ERP systems were formatted into the questionnaire, which was tested on two academics, experts in the field of Lean tools and ERP systems. This test was undertaken to improve the reliability and validity of the questionnaire. Thereafter a questionnaire was sent to the SMEs in order to determine the importance weight of CSFs from the respective SMEs. The time to complete the questionnaire was set at not more than 15 minutes, providing maximum information with minimum participant disruption, thus providing reliable answers to pertinent questions. The data collection process involved SMEs of differing size in terms of employee number, in the manufacturing sector, located in the North-East of England. The respondents were senior project managers; such people have rich understanding of the aims, issues, and outcomes of their companies. Figure 1 shows the method of the research of the SMEs who were contacted by telephone to discuss the possibility of taking part in this research, six of whom agreed to their involvement by completing the questionnaire dispatched and returned by electronic mail. The respondents were asked to categorise the factors based on their importance; the Likert Scale used provided ranges from 1 to 4 to indicate the importance of the factor, as shown in Table 1.

\begin{tabular}{cl}
\multicolumn{2}{c}{ Table 1 importance weighting } \\
\hline Scale & Importance $(F)$ \\
\hline 1 & Not important \\
2 & Slightly important \\
3 & Important \\
4 & Very important \\
\hline
\end{tabular}

In order to determine the importance weighting of the factors from collected data, the following statistical techniques were used to analyse the data. This method was introduced by Sadi and Al-Hejji (2006) in which the Frequency index (F.I) is calculated using a formula ranks CSFs based on their importance weight as identified by the participants.

$(F . I)(\%)=\sum_{a=1}^{4} a(n / N) * 100 / 4$

Where: 
$a$ : is the constant expressing weighting given to each response (ranges from 1 for not important up to 4 for very important).

$n: \quad$ is the frequency of the responses.

$N: \quad$ is total number of responses.

$I W: \quad$ important weight.

$I W: \quad=[(\mathrm{F} . \mathrm{I})(\%)] / 100$.

Figure 1 Scenario of the research methodology.

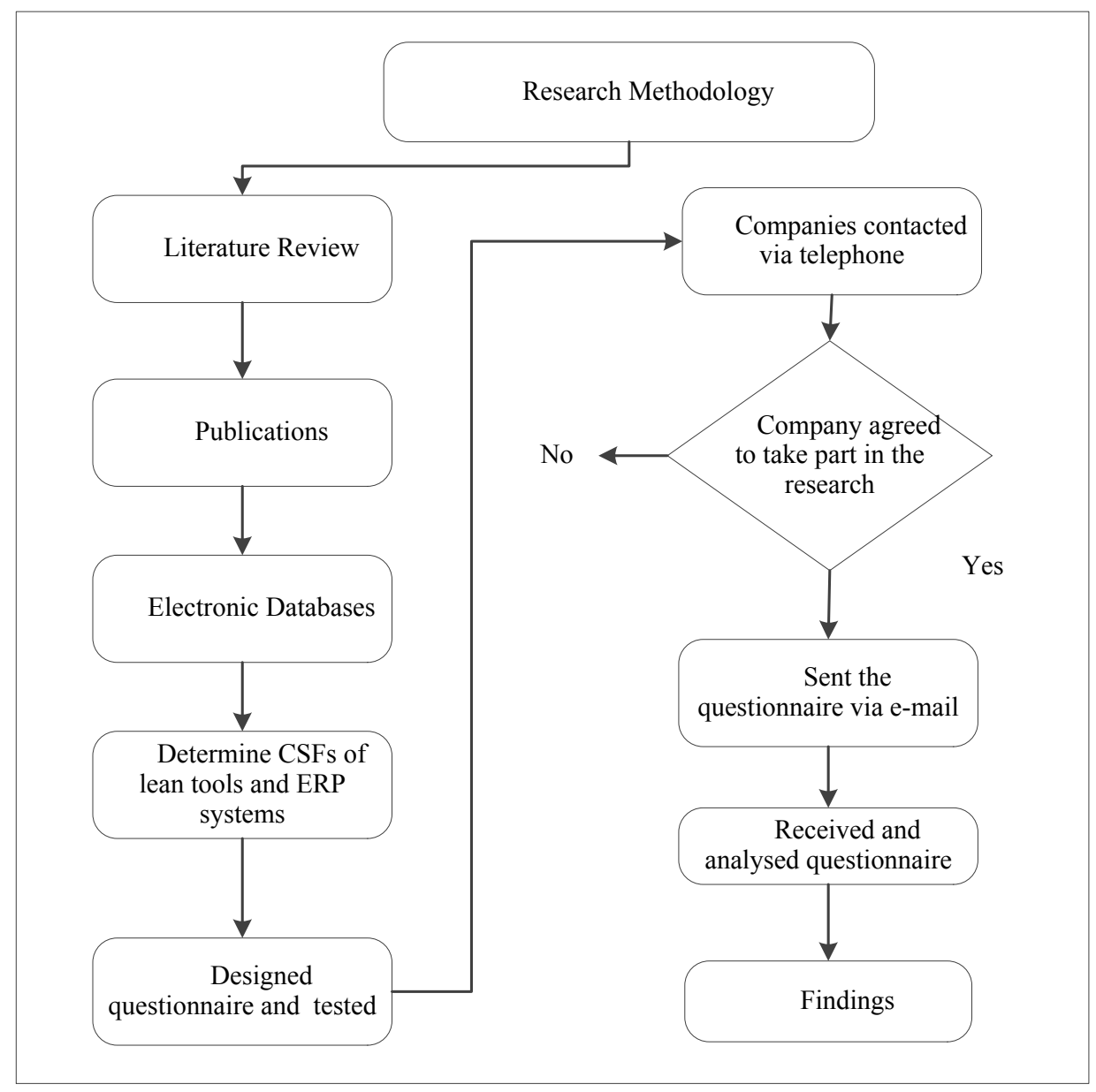

\section{Results}

The results of the study are presented in two main sections. In the first section contains the CSFs literature review. In the latter section, the results obtained from analysis of the questionnaire are presented. From the literature review it was observed that, despite the need of both Lean tools and ERP systems in SMEs, the amount of research conducted on this issue was limited. Therefore, more research is required to build adequate knowledge of this topic. However, it highlighted that the numbers of studies carried out on CSFs of ERP systems were greater than that of Lean tools.

As a result, a larger number of CSFs associated with ERP systems have been found compared with the number found in studies associated with Lean tools. Carrying out the methodology of this study, 22 of CSFs of ERP and 18 CSFs of Lean tools were determined and they are shown in Tables 2 and 3. 
In the second section, the statistical technique, mentioned previously, was conducted to determine the importance weighting (IW) of each CSF based on the participants' answers.

Table 2 presents the IW of CSFs of Lean tools. It notes that the most important factors are the following: Effective Communication (ID15), Determine Goals and Objectives (ID13), Commitment of the Top Management (ID1), Lean Champions (ID9) and Problem Solving by Involving People (ID 4). The less important CSFs are Visible Management Commitment (ID11), Views and Understand Lean as a Philosophy rather than another Strategy (ID10).

Table 2 CSFs of Lean tools

\begin{tabular}{|c|c|c|c|}
\hline$I D$ & CSFs of Lean tools & $I W$ & Rank \\
\hline ID 1 & Commitment of the top management & 0.83 & 6 \\
\hline ID 2 & Standardization & 0.66 & 3 \\
\hline ID 3 & Realistic timescales for changes & 0.66 & 3 \\
\hline ID 4 & Problem solving by involving people & 0.75 & 5 \\
\hline ID 5 & Continual evaluation during the Lean effort is critical & 0.62 & 2 \\
\hline ID 6 & Getting shop floor commitment and employee trust & 0.70 & 4 \\
\hline ID 7 & Involve and value employees at all levels of the organization & 0.62 & 2 \\
\hline ID 8 & Financial Capabilities & 0.66 & 3 \\
\hline ID 9 & Lean champions & 0.75 & 5 \\
\hline ID 10 & views and understand Lean as a philosophy rather than another strategy & 0.62 & 2 \\
\hline ID 11 & visible management commitment & 0.58 & 1 \\
\hline ID 12 & view Lean as a long term journey & 0.66 & 3 \\
\hline ID 13 & Determine goals and objectives & 0.83 & 6 \\
\hline ID 14 & Comprehensive training and education & 0.70 & 4 \\
\hline ID 15 & Effective Communication & 0.87 & 7 \\
\hline ID 16 & Effective leadership & 0.62 & 2 \\
\hline ID 17 & Change in organizational culture & 0.70 & 4 \\
\hline ID 18 & Highly motivation of staff to improve the service & 0.75 & 5 \\
\hline
\end{tabular}

Table 3 presents the IW of 22 CSFs of ERP systems in terms of participants' point of view. The top five for CSFs are: Top management support (ID2), Clear Goals and Objectives (ID17), Effective Communication (ID 1), Business Process Reengineering (ID 12), User Training and Education on Software (ID 13).

Table 3 CSFs of ERP systems

ID CSFS of ERP systems IW Rank




\begin{tabular}{|c|c|c|c|}
\hline ID 1 & Effective Communication & 0.83 & 6 \\
\hline ID 2 & Top management support & 0.87 & 7 \\
\hline ID 3 & Project team Organization and Competence & 0.75 & 5 \\
\hline ID 4 & Sponsorship & 0.66 & 3 \\
\hline ID 5 & Legacy system management & 0.66 & 3 \\
\hline ID 6 & Monitoring and evaluating progress & 0.66 & 3 \\
\hline ID 7 & Project champion & 0.70 & 4 \\
\hline ID 8 & ERP Package Selection & 0.62 & 2 \\
\hline ID 9 & Vendor Support & 0.58 & 1 \\
\hline ID 10 & Financial Resources & 0.62 & 2 \\
\hline ID 11 & Empowered decision makers & 0.66 & 3 \\
\hline ID 12 & Business Process Reengineering & 0.75 & 5 \\
\hline ID 13 & User Training and Education on Software & 0.75 & 5 \\
\hline ID 14 & Project Management & 0.58 & 1 \\
\hline ID 15 & Appropriate use of consultants & 0.58 & 1 \\
\hline ID 16 & Trust between partners & 0.75 & 5 \\
\hline ID 17 & Clear Goals and Objectives & 0.87 & 7 \\
\hline ID 18 & Change Culture & 0.62 & 2 \\
\hline ID 19 & Change Management & 0.66 & 3 \\
\hline ID 20 & User involvement and participation & 0.66 & 3 \\
\hline ID 21 & Use of Consultants Services & 0.62 & 2 \\
\hline ID 22 & System Technological & 0.70 & 4 \\
\hline
\end{tabular}

In order to verify the Assumption 1 which is "There are some common factors among CSFs of Lean tools and ERP systems" the cross-comparison method shown in Figure 2 was carried out to identify whether there was, similarity between CSFs for ERP systems and Lean tools, this was conducted by comparing each CSF of ERP systems with CSFs of Lean tools.

Figure 2 An approach to identify similarity of CSFs

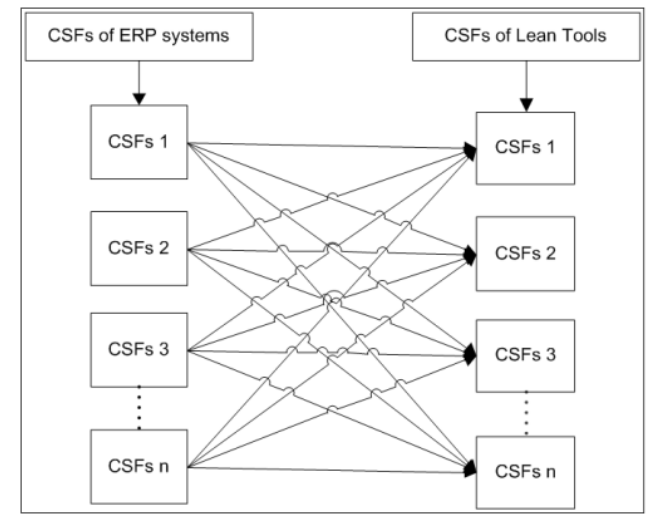


The outputs were that ten CSFs were identified, showing a similarity between the CSFs of Lean tools and that of ERP systems; these factors are presented in Table 4 and in Figure 3.

Table 4 similar CSFs.

CSFs IW of CSFs Lean IW of CSFs ERP

1. Financial Resources

2. User Training and Education

3. Monitoring and evaluating progress

4. Project champion

5. Trust between partners

6. User involvement and participation

7. Top management support

8. Effective Communication

9. Change Culture

10. Clear Goals and Objectives

0.66

0.625

0.70

0.75

0.62

0.66

0.75

0.70

0.70

0.75

0.62

0.66

0.83

0.87

0.87

0.83

0.70

0.62

0.83

0.87

Figure 3 Similar CSFs

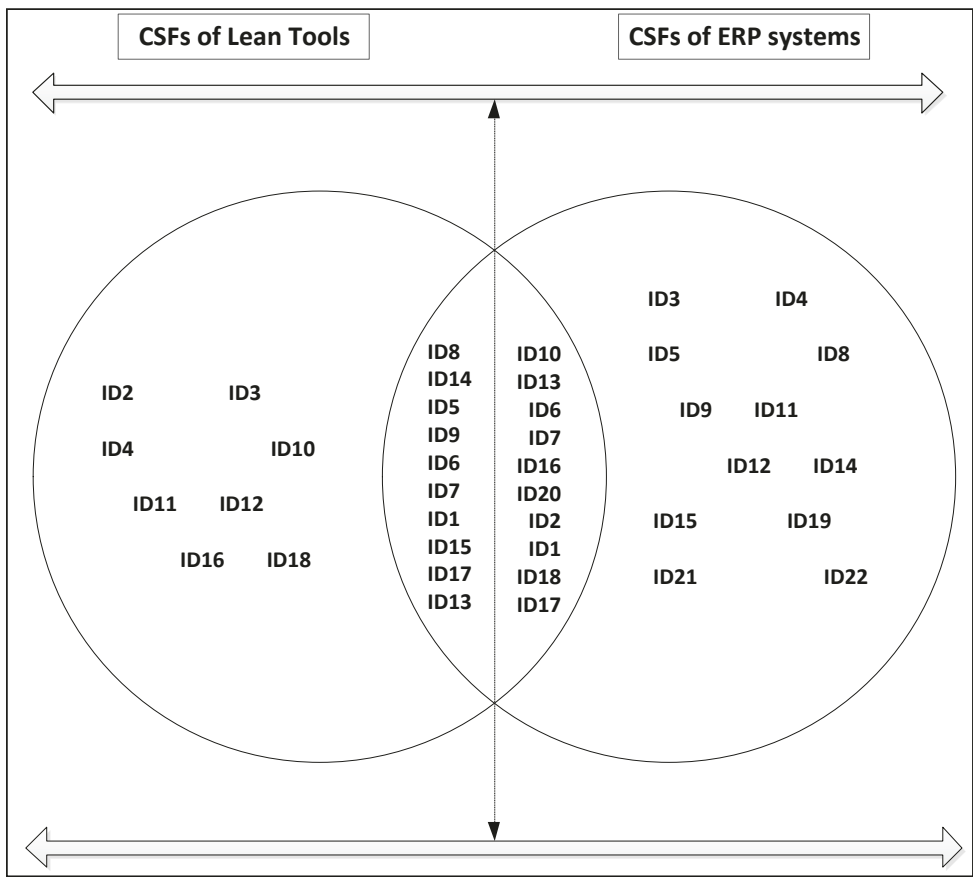

In order to verify the Assumption 2 "There is a high degree of correlation between CSFs of Lean tools and ERP systems" the correlation test was conducted using the Statistical Product and Service Solutions (SPSS) software package on these ten CSFs. The results of the correlation test show that there is a positive relationship between CSFs of Lean tools and ERP systems, as shown in Table 5; a high correlation of $\mathrm{r}=0.798$, and a significant level of 0.006 , which is less than 0.05 , means that the correlation is significant and can be properly realised in practice. Figure 4 illustrates the CSFs are linearly related. Although these factors have a strong 
positive correlation, it does not necessarily imply that one is the cause of the other. Nevertheless, these results suggest that the CSFs shown in Table 4 should be given high priority when companies attempt to adopt either approach.

IW of CSFS of Lean

tools
Pearson Correlation

Sig. (2-tailed)

$\mathrm{N}$

IW of CSFS of ERP
Pearson Correlation

Sig. (2-tailed)

$\mathrm{N}$
10

\section{$0.798^{* *}$}

0.006

10
IW of CSFS of

ERP

**. Correlation is significant at the 0.01 level (2-tailed).

Figure 4 Scatterplot correlations of CSFs

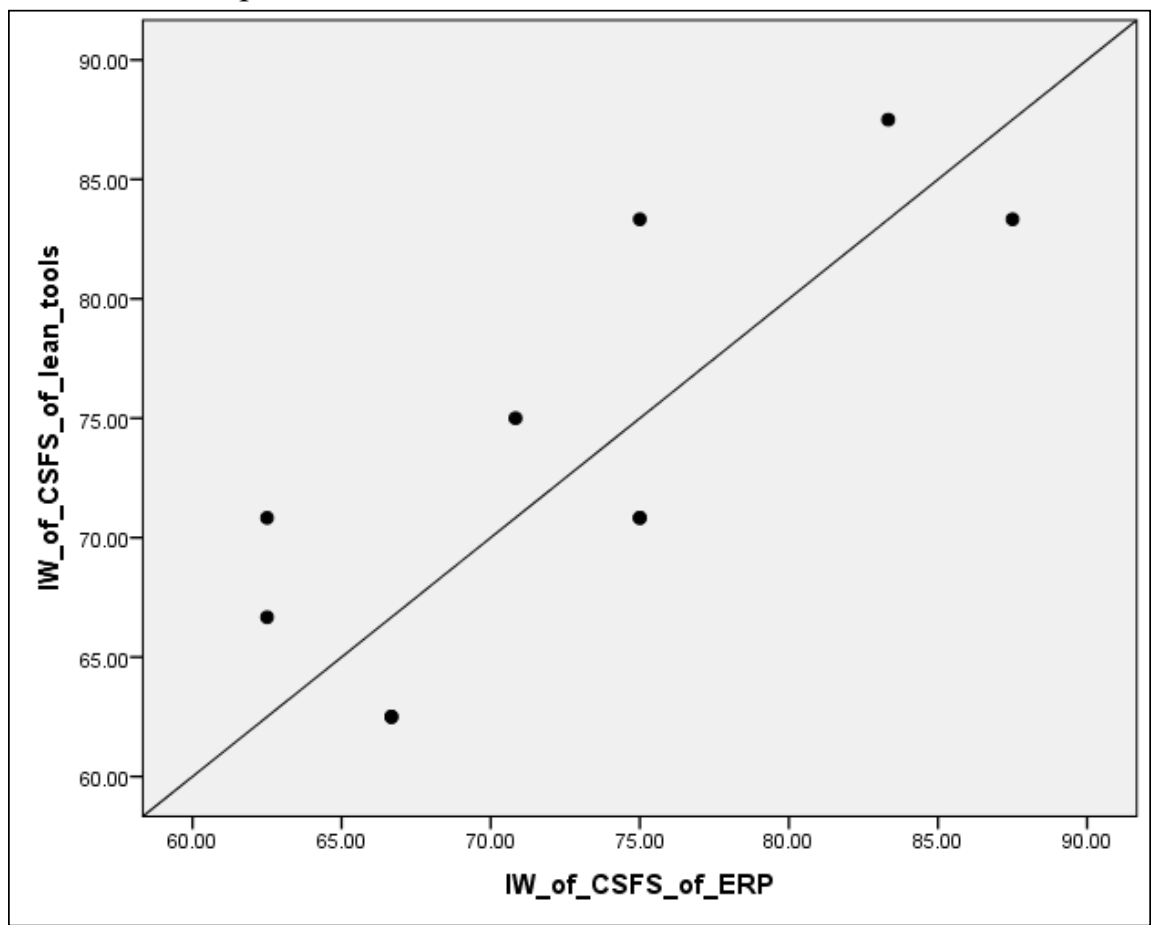

\section{Discussion}

Prior studies have documented the CSFs of Lean tools and CSFs of ERP systems. However, most of these studies have focused either on Lean tools or on ERP systems. This study aims to determine the most important CSFs which impact on the implementation of Lean tools and ERP systems within SMEs, and also the examination of whether there is a relationship between these factors. 
The literature review evidences that in order for SMEs to win the market competition, they need to improve several business attributes such as quality, effectiveness, delivery, and flexibility. Therefore, Lean tools and ERP systems appear to be the most relevant techniques that can provide the SMEs with all of these needs. However, there are other techniques that share similar benefits such as TQM, Six Sigma, and MRP II. Lean tools and ERP systems have some advantages. Lean tools consist of various tools which provide the SMEs with an opportunity to select the tool which is most suitable and applicable for their processes and strategy; thus, the company can adopt the appropriate Lean tool in a piecemeal manner; furthermore, there are many ERP systems that SMEs can select and implement; any one of which may meet their needs. Research indicated that there were a larger number of studies carried out on the CSFs of ERP systems compared with that of Lean tools; emphasising the need for further study CSFs which affect Lean tools.

The literature indicated that many CSFs influence the implementation of Lean tools and ERP systems. However, previous studies have provided limited empirical evidence on how these CSFs rank in terms of importance in the implementation of Lean tools and ERP systems. According to the findings of the current study, participation in the survey has emphasised that implementing Lean tools and ERP systems are heavily reliant on top management commitment and support as well as effective communication. It appears from the findings that issues related to top management are primarily seen as the main way to implement Lean tools and ERP systems. This finding is in line with that of many previous studies, (Hilton and Sohal, 2012; Doolen. et al., 2008). It has often been emphasised that commitment of top management, and having appropriate and effective communication in place can increase the successful implementation of Lean tools and ERP systems. Although those who participated in this research gave high ratings to both top management commitment and effective communication as key factors for the successful implementation of Lean tools and ERP systems, it was not certain, in the respective minds of the participants, how they could best augment and support the changes. This may in part be related to limitations of employee knowledge within the respective SMEs. However, SMEs fail to implement Lean tools and ERP systems, (Sohal and Egglestone, 1994; O'Corrbui, and Corboy, 1999; Seymour et al., 2007; Chronicles, 2003). The most important reason behind this failure may be that the managers involved with the said implementation lack contemporary knowledge on Lean tools and ERP systems and their respective implementation. There were some similarities between CSFs of Lean tools and ERP systems. Table 4 illustrated that among the identified CSFs of the Lean tools and ERP systems there are ten similar factors. This justifies Assumption 1, that there are some common factors among CSFs of Lean tools and ERP systems. Further analysis carried out using SPSS software has highlighted the existence of a positive correlation between these ten similar CSFs; justifying Assumption 2 that there is a high degree of correlation between CSFs of Lean tools and ERP systems.

This study indicates ten CSFs which have a significant impact on the implementation of both Lean tools and ERP systems; therefore, the management of the SMEs may need to provide greater attention to these factors. It would appear that companies managing these CSFs effectively will have a higher probability of successful implementation of Lean tools and ERP systems. The practical implications of the CSFs discussed in this paper are targeted at Lean tools and ERP implementation. Thus, SMEs will use these factors as a guide for future implementations, in order to assist them in avoiding the failures that have been experienced by other SMEs in previous attempted implementations. The research results did not indicate differences between CSFs of SMEs and those of large companies; for instance top management commitment was found to be of critical importance in this study, and also in similar studies of large companies. Therefore, although there are many significant differences between SMEs and large companies, clearly company size does not have a significant impact on CSFs of Lean tools and EPR systems.

\section{Conclusions}

The study aimed to determine the most important CSFs which have the strongest impact on the implementation of Lean tools and ERP systems within the SMEs. The identified CSFs will provide a useful insight for the enhancement of the critical decision-making process needed for the delivery of corporate strategic ambitions towards the implementation of Lean tools and ERP systems. In this study a literature survey was 
carried out including 18 CSFs of Lean tools and 22 CSFs of ERP systems. These CSFs were formatted in a questionnaire, sent electronically to ten SMEs, with the intent to determine the importance of each factor. Study results were generated from the return numbers, whilst pertinent, they may be insufficient to provide a generalised theory for all sectors. However, this research enhanced the understanding of the nature of CSFs of Lean tools and ERP implementation in SMEs, indicating the respective priority of factors in order to use the companies' resources and effort in the most opportune manner, thus maximising the possibility of successful implementation. From the research results and subsequent discussion, a number of conclusions have been drawn. First, the study supports previous research; the defining and study of CSFs in both Lean tools and ERP systems is a very important area of research; the identification of the CSFs of Lean tools and ERP systems and determining their respective importance in the implementation of change can enhance the understanding of this essential and complex topic in the specific context of SMEs. The second conclusion of the study is that top management commitment and effective communication were critically important CSFs. Thirdly; the research findings revealed that there was a positive relationship between some of the CSFs of Lean tools and those of ERP systems. Finally, it emerged that SMEs have a high ratio of failure of implementing Lean tools and ERP systems. The most important reason may be their limited resources and knowledge renders a greater challenge for SMEs. Based on the research findings, recommendations have been proposed for SMEs particularly in the North-East of England. The top management commitment and effective communication are the key factors in the successful running of SMEs and their adoption of either Lean tools or ERP systems. Therefore, top management are required to fully support all initiatives that the company implements in order to ensure performance improvement; also the SME's communication system requires to be optimised, thus assisting the company to increase performance.

This work is supported statistically. The authors have noted that, despite the large numbers of SMEs in the North-East of England, they share similar attributes, such as knowledge levels and culture. Thus, the result drawn from this small sample can reflect a large number of SMEs within the region. However, it has to be stated that there are limitations to this study due to the sample size; this opens up the potential for future work to be undertaken with larger samples utilising the same methodology which would afford the opportunity to provide further support for findings of this study.

\section{References}

1. Abdulla, F. (2003) Lean Manufacturing tools and Techniques in the process industry with a focus on steel. PhD thesis, University of Pittsburgh, United States.

2. Ahmad, M., and Pinedo Cuenca, R. (2013) 'Critical success factors for ERP implementation in SMEs', Robotics and Computer-Integrated Manufacturing, Vol.29, Iss. 3, pp.104-111.

3. Alaskari, O. Ahmad, M. Dhafr, N., and Ruben C. (2012) 'Critical Successful Factors (CSFs) for Successful Implementation of Lean Tools and ERP Systems'. In Proceedings of World Congress on Engineering Conference, 4-6 July 2012. London, U.K.

4. Sun A., Yazdani A, and Overend, J. (2005) 'Achievement assessment for enterprise resource planning (ERP) system implementations based on critical success factors (CSFs)', International Journal of Production Economics, Vol. 98 No. 2, pp. 189-203.

5. Al-Mashari M. and Al-Mudimigh, A. (2003), 'ERP implementation: lessons from a case study', Information Technology and People, Vol. 16 No. 1, pp. 21-33. 
6. Alvarez R., Calvo, R., Peña, M. and Domingo, R. (2009) 'Redesigning an assembly line through lean manufacturing tools', International Journal of Advanced Manufacturing Technology, Vol. 43, No.9-10. pp. 949-58.

7. Sohal, A. and Egglestone A, (1994) 'Lean Production: Experience among Australian Organizations' International Journal of Operations \& Production Management, Vol. 14 Iss: 11, pp.35- 51.

8. Sadi, A. and Al-Hejji, S. (2006) 'Causes of delay in large construction projects', International Journal of Project Management, Vol.24, No. 4, pp.349-357.

9. Baker, P. (2002) 'Why is lean so far off?' Works Management, October, pp. 1-4.

10. Farzad, B. and Wong, K.Y (2011) 'Lean performance evaluation of manufacturing systems: a dynamic and innovative approach', Procedia Computer Science, Vol. 3, pp. 388-395.

11. Bernroider, E. and Koch, S.(2001) 'ERP selection process in midsized and large organizations', Business Process Management Journal, Vol. 7 No. 3, pp. 251-7.

12. Bicheno, J. and Holweg M. (2009) 'The Lean Toolbox, The Essential Guide To Lean Transformation' PICSIE Books, Buckingham.

13. Boynton, C. and Zmud, W. (1984) 'An assessment of critical success factors'. Slogan Management Review, Vol. 25, pp. 17-27.

14. Brent, S., da Silveira, G., and Balakrishnan, J. (2009) 'ERP implementation at SMEs: analysis of five Canadian cases', International Journal of Operations \& Production Management, Vol. 29 Iss: 1, pp.4-29.

15. Brotherton, B. and Shaw, J. (1996) 'Towards an identification and classification of critical success factors in UK hotels Plc'. International Journal of Hospitality Management, Vol.15 No 2, pp.113-135.

16. Tyson, B. and Heath, R. (2009) 'Reconceptualizing the effects of lean on production costs with evidence from the F-22 program', Journal of Operations Management, Vol. 27 No. 1, pp. 23-44.

17. Chronicles Version 3.0. (2003), The Standish Group: West Yarmouth, MA.

18. Chockalingam, A. and Ramayah, T. (2013) 'Does the organizational culture act as a moderator in Indian enterprise resource planning (ERP) projects?: An empirical study', Journal of Manufacturing Technology Management, Vol. 24 Iss: 4, pp.555 -587.

19. Doom, C., Milis, K., Poelmans S., and Bloemen, E. (2010) 'Critical success factors for ERP implementations in Belgian SMEs', Journal of Enterprise Information Management, Vol. 23 Iss: 3, pp.378-406. 
20. Daniel, R. (1961) 'Management information crisis'. Harvard Business Review, Vol. 39 No. 5, pp. 111-121.

21. Davenport, H. (1998) 'Putting the enterprise into the enterprise system', Harvard Business Review, Vol. 76 No. 4, pp. 121-31.

22. European Commission. (2012) 'small and medium sized enterprises in 2011: situations per EU Member State’. http://europa.eu/rapid/press-release_MEMO-12-783_en.htm (Accessed 28 July 2013)

23. Fitz-Gerald, L. and Carroll, J. (2004) 'The role of governance in ERP system implementation', The Communications of the ACM, Vol. 15 No. 4, pp. 72-83.

24. Freund, P. (1988) 'Planner's guide Critical Success Factors', Planning Review, Vol. 16, No. 4, pp. 20-23.

25. Gupta, M. and Cawthon, G. (1996) 'Managerial implications of flexible manufacturing for small/medium-sized enterprises', Technovation, Vol. 16 No. 2, pp. 77-83.

26. Christopher, H. and Light, B. (1999) 'A critical success factors model for ERP implementation', IEEE Software, Vol. 16 No. 3, pp. 30-36.

27. Huin, F. (2004) 'Managing deployment of ERP systems in SMEs using multi-agents', International Journal of Project Management, Vol. 22 No. 6, pp. 511-17.

28. Sean, J., Carter, P. and Zmud, R. (2005) 'A comprehensive conceptualization of post-adoptive behaviors associated with information technology enabled work systems', MIS Quarterly, Vol. 29 No. 3, pp. 525-57.

29. Jiju, A., Kumar, M., and Madu, C. (2005) 'Six sigma in small- and medium-sized UK manufacturing enterprises: Some empirical observations', International Journal of Quality \& Reliability Management, Vol. 22 Iss: 8, pp.860-874

30. Gopal, K., Malek, A., and Tambi, B. (1999) 'Total Quality Management in UK Higher Education Institutions' Total Quality Management, Vol 10 No.1, pp. 129-153.

31. Langenwalter, G., (2000) Enterprise Resources Planning and Beyond: Integrating Your Entire Organization. St. Lucie Press, Boca Raton, FL.

32. Joel, L., and Bruno, A. (1984) 'Identifying and using critical success factors'. Long Range Planning, Vol.17, No 1. pp. 23-32.

33. Majed, A. (2000) Enterprise-Wide Information Systems: The Case of SAP R/3 Application. In Proceedings of the Second International Conference on Enterprise Information Systems, pp 3-8. 
34. Markus, L., Axline, S., Petrie, D. and Tanis, C. (2000b) 'Learning from adopters' experiences with ERP: problems encountered and success achieved', Journal of Information Technology, Vol. 15, No 4. pp. 245-65.

35. Marnewick, C., and Labuschagne, L. (2005), 'A conceptual model for enterprise resource planning (ERP)', Information Management and Computer Security, Vol. 13 No. 2, pp. 14455.

36. Matt, T. (2008) 'Template based production system design', Journal of Manufacturing Technology Management, Vol. 19 No. 7, pp. 783-97.

37. Joseph M., Small, M., and Chen, I. (2003) 'Implementing ERP in small and mid-size manufacturing firms', International Journal of Operations \& Production Management, Vol. 23 No. 8, pp. 850-71.

38. O'Corrbui, D. and Corboy, M. (1999) 'The seven deadly sins of strategy', Management Accounting, No. 10, pp. 1-5.

39. Oakland, J.S. (1995) Total Quality Management: Text with Cases, Butterworth-Heinemann Ltd, Oxford.

40. Panaroma Consulting (2010) available at: http://panorama-consulting.com/wpcontent/uploads/ 2009/10/2011-ERP-Report.pdf. (Accessed: 29 ${ }^{\text {th }}$ January 2013).

41. Parr, A., and Shanks, G. (2000) 'A model of ERP project implementation', Journal of Information Technology, Vol. 15 No. 4, pp. 289-304.

42. Ramayah, T., and May-Chiun Lo. (2007) 'Impact of shared beliefs on "perceived usefulness" and "ease of use" in the implementation of an enterprise resource planning system', Management Research News, Vol. 30 Iss: 6, pp.420-431.

43. Rockart, F. (1979) 'Chief executives define their own data needs'. Harvard Business Review, Vol.57, No.2, pp,81-93.

44. Hilton, R., Sohal, A. (2012) 'A conceptual model for the successful deployment of Lean Six Sigma', International Journal of Quality \& Reliability Management, Vol. 29 Iss: 1, pp.54 -70.

45. Salem, O., Solomon, J., Genaidy, A. and Minkarah, I. (2006) 'Lean construction: from theory to implementation', Journal of Management in Engineering, Vol. 22 No. 4, pp. 168-75.

46. Judy, S., and Vessey, I. (2002) 'Managing risks in enterprise systems implementations', Communication of the ACM, Vol. 45 No. 4, pp. 74-81.

47. Seymour, L., Makanya, W. and Berrange, S. (2007) 'End-users' acceptance of enterprise resource planning systems: an investigation of antecedents'. In proceedings of the 6th Annual ISOnEworld Conference, April 11-13, 2007, Las Vegas, NV. 
48. Rachna, S., and Ward, P. (2007) 'Defining and developing measures of lean production', Journal of Operations Management, Vol. 25, N.4, pp. 785-805.

49. Sternad, S., Bobek, S. (2006) 'factors which have fatal influence on ERP implementation on Slovenian organizations', Journal of information and organizational sciences, vol. 30, No. 2 , pp. 279-293.

50. Khaled, S. (2007) Application of lean techniques for the service industry: A case study M.S., Southern Ilinois University at Cabondale, 104, pp; 1446981.

51. Lin, T., Luarn, P., and Lo, P. (2004) 'Internet market segmentation -an exploratory study of critical success factors’. Marketing Intelligence \& Planning, Vol. 22 Iss: 6, pp.601- 622.

52. Doolen, T., Van Aken, E., Farris, J., Worley, J and Huwe, J. (2008) 'Kaizen events and organizational performance: a field study' International Journal of Productivity and Performance Management, Vol. 57 Iss: 8, pp.637-658.

53. Underdown, R and Tallury, S. (2002) 'Cycle of success: a strategy for becoming agile through benchmarking', Benchmarking: An International Journal, Vol. 9 No. 3, pp. 278-92.

54. Womack, J., Jones, T., and Roos, D. (1990) 'The Machine that Changed the World', Rawson, Associates, New York, NY. 